fying cerebral oppression from malaërated blood, and gradually deepening, as the case advances, into the perfect coma, with or without convulsions, which closes the scene.

Detached portions of false membrane, sometimes of a tubular form, and of considerable size, are, it is well known, occasionally ejected during an attack of croup; but it is matter of common observation that, in general, no favourable :ugury is derivable from the circumstance, for that it occurs oftenest towards the close of a hopeless case. Does not this tell us of relaxation of the glottidean constriction, delayed until irretrievable injury has been done to the brain by the prolonged circulation through it of non-arterialised blood?

The presence of false membrane in the lower part of the trachea and in the bronchi, with copious mucus or mucopurulent secretion in these situations, are appearances more especially appertaining to the asthenic variety of the same disease, to cases comparatively slow in thcir course, and little marked by cessations and aggravations of dyspncar; because in these the inflammation has been more moderate in degree than in the more acute form, and has excited a less energetic contraction of the glottidean unscles, allowing time for the extension of the morbid action and its results farther down the tube.

A remarkable regularity, as regards the time of invasion of the developed stage of croup, has been noted by all writers on the subject, and is indeed a well known characteristic of the disease. In one case, the premonitory catarrhal symptoms may be present for a day or two preceding for akout the same length of time, in another, slight uneasiness in the throat may be complained of, and, if this have attracted notice, inspection may reveal the diphtheritic exudation, with surrounding redness on the tonsils and uvula ; in a third, the little patient may have retired to rest in apparently perfect health ; but, in all, the probability is, that the first announcement of the accession of the stage in question of this malady-the first hard ringing coughwill occur early in the night, and during sleep; and the same proclivity to nocturnal invasion or aggravation of stridor, although it has excited more general attention in this the most common disease of the class, is observable, and has also been recognised, in the other forms of laryngotracheal inflammation.

The explanation of this peculiarity will flow from the doctrine above advanced regarding the rutionale of stridulous cough and respiration. "Volition", says Dr. Marshall Hall (On the Diseases and Derangements of the Nervous System, p. 254), " has a constant influence over some of the muscular actions, of which we are almost unconscious, and which we only discover by carefully observing the effects of its subtraction. The acts of respiration, origiuating, as they do, in the reflex function of the spinal marrow, are nerertheless regulated and rendered equable by this silent but constant influence and agency of volition." And thus a degree of inflammatory action in the laryngeal mucous membrane which is insufficient to excite the glottidean contraction, when the muscular apparatus concerned in it is under the full control of the cerebral system, will be adequate to the production of the act in question, during slecp, when this controlling power is greatly in abeyance.*

Keith, July 1851.

$$
\text { [To be continued.] }
$$

- As might be anticipated, a similar tendency will be found to exist in other affections involving the perversion, or morbid excitatiun of the rettex function-examples of which unust of en present themselves to the medici practitioner. fumiliar one may be ineutioned, occurring iu some cases uf fracture, in which the patient no sooner drons asleep thail he is aroused by pacture, ill which the patient no sooner drops asleep than he is aroused by painful twitchings in the muscles of the injured part, which cease when he wide awake, only to recur when he begius to dose again-unless the excitumotor system, which, in the language of its discoverer, "never sleeps", can be coaxed into temporary quiescence by the administration of an opiate. A somewhat whimsical exemplificntion of this physiological law is occasioually experienced by a friend of the writer in his own person. When a corn, situ ated on the lateral aspect of the little toe of his right foot, has attained a certain size, he cannot go to sleep, if he recline on the right side- so as to allor the excrescence to rest upon the bed-Without the certainty of being innediately after aroused by nudden and powernl contraction ibut accompanie by no feeling of pain) of the fexors of the thigh nnd len of the extremity on which his tormentor is located, and he can only escepe a repetition of the the other as to wand off pressure from the tender toe, or by lying on his other
PHYSIOLOGICAL AND PRACTICAL STUDIES. By BENJAMIN W. RICHARDSON, M.D.

$$
\text { No. II. }
$$

OX THE ETFECTS OF TIIE HORIZONTAL POSITION OF THE BODY IN SYNCOPE; WITH OBSERVATIONS ON THE RELATIONSHIP THAT EXISTS BETWEEN TUE BR.AIY AND HEART.

[Read in abstract before the Physiological Section of the Medical Society of Loudon, on A pril 10th, 1851.]

\section{PABT I.}

ThI simple fact, that the horizontal position of the body affords oftentimes marked and immediate relief to those serious symptoms which follow upon a sudden failure in the action of the central organ of the circulation, is so often observed and so generally known, that it ranks in popularity with the well understood medical truths, salts purge and opium stupifies. But I do not know that any very signal and distinct attempt has ever been made by the physiological inquirer to explain the principles on which this excellent and simple remedial measure produces its good effects.

One view, however, on this subject has fixed itself in the professional mind, and this view, though it has an indirect source and is used more for explaining and strengthening other theories than as illustrating specially the mode in which the recumbent position becomes useful in syncope, requires to be carefully and thoroughly refuted before an explanation of the simple fact can be entered on at all.

The view to which I refer, is that which presumes that, during failure of the circulation, the nerrous system, sharing seriously in the depression, fails to supply the heart with nervous power; that, by laying the head low, in such cases, the blood is allowed to flow more freely to the brain and medulla; and that these centres, regaining energy by this process, react on the heart and supply it with renewed vigour.

The theory here supplied has been spoken of by many authors. Thus, Dr. Alison of Edinburgh, in his excellerit work, Outlines of Pathology and Practice, p. 536, says, "When, therefore, we see a fit of syncope or a tendency to it, brought on either by loss of blood, or by purging, or by sweating, or by alteration of the distribution of the blood, as by drawing off the fluid in ascites, we may reasonably infer that the immediatc cause of the complete failure of the heart's action is not the mere diminution of the stimulus acting on the heart, but a change in the condition in the nervous system."

"This secondary action or reaction on the heart," le continues, "of diminished pressure on the brain (originally consequent in some cases on deficient action of the heart itself) is very important to be kept in mind in all speculations as to syncope; and explains the well-known effect of the horizontal posture, not only on the nervous symptoms in syncope, but on the affection of the heart itself. This," he remarks, " is one of the considerations formerly cited to prove, that, in the living body, the actions of the heart are subject to an influence and control, from certain changes which take place in the nervous system; and which seem to extend over the whole of that system, and to act at a peculiar advantage on the heart, as an organ connected through the ganglionic nerves, with all parts of the cerebrospinal axis."

In the article on Syncope in the Cyclopedia of Practical Med: ine, Dr. Ash says that "the recumbent position is gener illy found to promote recovery, apparently by facilitating the restoration of the cerebral circulation."

Sir George Leferre, in his work bearing the remarkable title of $A n$ Apology for the Nerves, makes also the following

side-the dorsal deculitus being inade cariare to him by the hay Ephialtes. Fur some time after the curn has been pared, or "picked", he may enjoy his favourite posture in bed, secure, without preciation, from the attacks of this enciny to his repuse.

Thut some discases have a disposition to arise, by preference, at uight, is an old observacion. " Nounnllos aluritur," sil's lle'terden, "post primum somi terups: "unol in morbis ex distensione frecineus est." probably these murthex distentiunc are ot the chis to which the fure oing remark huce reforence affectiuns in examining whose promiuent characteristic, I have remplo logy-that supplied us by the labours of the illustrious Marshall Hall. 
remarks in spenking of syncope : "I Iet us give to the blood its due in restoring the heart's action. In its retreat from the brain it is choked up in the citadel, congested in the extremities. It cannot overcome the laws of gravity, having lost its vis $d$ tergo; and as the difficulty is increased by the erect, we seek relief mechanically by placing the patient in the recumbent posture, that the blood may flow more freely in a horizontal line." This disposition to swooning in an erect position, from robbing the brain of its usual quantity of blood, is illustrated satisfactorily (according to Sir George) in the following case :- "A lady, past the middle age, was so subject to faint when in the erect posture that she was, although otherwise in good health, confined to her bed and sofa; as soon as she attempted to rise she felt faint or even 8wooned. The cause of this phenomenon for a long time baffled the skill of her medical attendant, till, by some accident, he discovered that she had immensely varicose veins in both legs; and in the erect posture these became reservoirs for the blood, which accumulated too much in them to be propelled forward; hence the balance of the circulation was deranged, and the brain, robbed of its usual quantity, manifested symptoms of its weakness. By the application of proper bandages, which supported the vessels in an erect posture, this distressing affection was orercome."

I could adduce many other authorities of great reputation who have endeavoured to illustrate further the theory here noticed; but I need not do so, inasmuch as a few moments of quiet reflection must afford to every one, who has the most general idea of the dynamical laws of the circulation, proofs of the fact that in the mere absence of the pulsating and regulating power of the heart, there can be no continued flow of blood to any organ of the body, however much the position of the body may be modified.

The very case referred to by $\operatorname{Sir} G$. Leferre corroborates this fact; and it is quite marvellous how he should hare been led to any such conclusion as that which he has given. There is no doubt that in the case he mentions the brain did not receive its due share of blood; but this was secondary to the fact that the propelling power of the heart had been to a great extent lost, through the mechanical impediment that existed in the course of the circulation. The bandage over the enlarged veins met this difficulty; and the heart, receiving a more free current of blood from the lower part of the body, which no longer acted as a capacious reservoir, had its action in no way suspended. But is it not obvious that blood detained in the lower extremities could not reach the brain without first passing through the chambers of the heart, and subsecpuently, under the influence of ventricular contraction, through the cerebral vessels? And is it not equally obvious, that if the mechanical support afforded by the bandage enabled the heart's stroke to be maintained with sufficicnt energy to feed the ressels of the head with blood, the result desired was obtained, and that it can be explained without, the necessity of having recourse to the idea of the maintenance of a nervous current or any other imaginary force?

But the theory may be objected to on other grounds: for it is easy to prove that if the failing heart really did receive some form of renewed force directly from the brain upon the body being laid horizontally, such force could not in the majority of cases re-establish the circulation; and this for the simple reason, that it is in rain to make the heart exert its contractile force, unless it be supplied at the same time with material on which to spend its exertions. In simple words, an empty heart cannot pour forth blood. Now, in a large number of cases of syncope in which the recumbent position does good, the circulation fails for the simple reason that the heart, being robbed of its blood, not only has nothing left to stimulate it to contraction, but has nothing left to propel. Hence in desperate cases, in addition to laying the body horizontally, we not uncommonly resort with good results to the operation of transfusing new blood into the exhausted vessels. But who would say that we thus drive the new blood into the system for the first and immediate purpose of stimulating the nervous centres by bringing blood into direct contract with them? The idea is abeurd-we thror in the blood that we may fill the heart with its own natural stimulus; and if we succeed at all in the operation, we do so because the heart receives and ro sponds to the draught of life with which we have favoured it.

I doubt not but that much of the importance of the theory I am now refuting has arisen out of the observation, that a fainting person soon recovers consciousuess after being laid in the recumbent position. In this observation, however, the actual connexion which exists between the restoration of consciousness and the recovery of the heart from its state of prostration has been misconstrued and inverted; i.e., an effect has been mistrken for a cause. I do not wish to say that too much importance can be attached to the retum of the mind's active functions; but $I \mathrm{am}$ anxious to uphold the idea that however wonderful, inscrutable, and immaterial those functions may be, which we are wont to include under the general term consciousness, they submit like every thing else to what is at least temporary change, under the infuence of those laws by which the material operations of the body are carried on. This is the case in syncope; whenever consciousness ceases during failing states of the circulation, it ceases in proportion with and as a consequence of the failure in the circulation; and what is more to the point, whenever consciousness returns after a syncope, it returns in proportion with and as the result of the return of the heart's action. In this light we may place consciousness side by side with common sensation, voluntary muscular action, and the development of animal heat.

The truth of the position I here take I have corroborated over and over again while observing syncopal conditions, both in the human subject and in animals of an inferior grade; and any other practitioner, who wishes to observe the same facts, need only watch carefully and without bias the recovery of a patient from a profound syncope. He will then find that the first and main sign of recovery is the return of the beart's beat, and that consciousness, warmth, and muscular action are always secondary to this phenomenon ; muscular movements appearing first, as a general rule, consciousness second, and warmth last. These observations indicate to a great extent, if not definitely, that the heart's action is repeated independently of any influence derived from the cerebro-spinal axis; since, as it is acknowledged by all that the encephalon and spinal cord are the only organs through which the mental faculties, sensation and volition, are manifested, it follows that such manifestations should always precede the restoration of the circulatory movements, if the latter depended on some kind of influence derived from the great centres of the nervous system.

Or take a contrary view, derived from the observation of another class of cases. It sometimes happens that the action of the heart fails in the most serious manner, while the functions of the nervous system remain in every respect perfect. Patients will not only often feel exceedingly faint, but will actually be so, with the heart's action at the lowest possible pitch compatible with the smallest remnant of life, and yet the mind will remain perfectly collected and calm. I have observed this often in cases of rapid hrmorrhage, and it is by no means uncommon in the sinking stages of exhausting diseases. In cholera cases, this occurrence sometimes stands out remarkably; especially in those instances where death takes place rapidly from the free and continuous alvine discharges, which, as Dr. Cormack has recently observed in his able essay on Cholera, reduce the system after the manner of a hæmorrhage; and a case of another kind has recently been related to me by Dr. Snow, in which, after the performance of a serious surgical operation, under the influenco of chloroform, the patient, when consciousness had fully returned, became alarmingly faint, with the pulse almost imperceptible, and the heart scarcely audible; the mind at the same time remaining perfectly active, collected, and calm.*

- The deaths of Incan and Senecs, which form 80 matked a figure in Roman history, were remarkable as showing how long the mind will remain entire duriug roished me operation of opening the reins. The reins of Lucan were opened in a wan bath, and when be falt himself atin- 
It is perhepe not feir to prow the point too far, that, in cares such as are here described, the functions of the nervous syatem remain unimpaired; while the action of the beart is inconstant and proutrated; inasmuch as the mere retention of the mental frculties does not prove that all the nervous functions are unimpaired. But the cases at least illustrate that there may exist the most serious derangement in the action of the circulating organ, without any corresponding and proportionate disturbance of the cerebral manifeetations.

Moreover, the brain, and indeed the whole of the cerebroapinal axis, may be absent from abnormal development and yet the circulation shall exist during all the period of intra-uterine life, and occasionally for some time afterwards. In such instances, we have ample evidence, not only that the heart has pulsated without the assistance of spinal cord and brain, but that it has done its work with sufficient power and regularity to carry on a very extensive and efficient nutritive process. The existence of acephalous monsters forms in truth one of the most important and least understood facts, with which the physiologist has to deal; since it points out how very much can be effected with the nerrous system in the lowest state of development, during conditions in which the active and independent functions, not of the mind alone, but of digestion and respiration, are unrequired. At all events, the inference is clear, that the inability to support an independent life on the part of the newly born acephalous monster does not accur because the heart cannot continue to beat in the absence of the nerrous centres, but because the other leading argans are unable to add their share of labour to the common task.*

The experiments of Wilson Philip and Fleurens, in which they removed the spinal cord and brain, and, by supporting respiration artificially, kept the heart pulsating, are a further confirmation of the truth that the heart claims no direct dependence on the cerebral spinal axis. Wilson Philip remarks, that when the whole of the spinal cord and brain are removed by the knife, from an animal that has been rendered senseless by a blow on the head, and whose respiration is supported artificially, the heart continues to pulsate, though the beat is thereby rendered very feeble. It cannot be cause for wonder that the heart beat should be feeble under such circumstances. For, in the first place, the amount of blood lost during the operation of sweeping out the brain and spinal cord is no slight matter.t Secondly, artificial respiration, however cleverly perforned, is a very inadequate representation of natural respiration. $\ddagger$ And thirdly, it must be remembered that the digestive process is suspended during the whole proceeding - a process which, though of less immediate importance, is in the end as vital as either respiration or distribution of blood. For, before any absolute fact could be arrived at, as to the intluence of artificial respiration in supporting the heart's move-

ing from the drain of blood, he repeated some of his own verses, descriptive of a wounded soldier ginking in a yiuilur manner.

Tacitus thus describes these events. Senccs having been condemned to die, and his wife determining to die with him--"eodem ictu biachia ferro exsolvunt. Seneca, quoniam senile corpus et parvo victu tenuatum lents effugis anguini prebebst, crurunn quoque et poplitum veuas abrumpit. Sevisque crucistıbus defessus, ne dolore sho nuimum uxoris infringeret, atque ipse visendo ejus tormenta al imputientium delaberetur, suadet in alind cuhiculum sbscedere. Et novissimo quoque momento suppeditante eloquentià, advocutis scriptoribus pleruque tralidit, quie, in vulgus edita ejus verbis, iuvertere supersedeo." ('Tacitus, Antıal. lib. xv, z 63.)

"Exin M. Annæi Lucani cædem imperat. Is protluente sanguine, ubi frigescere pedes manusque et paulation ab extremis cedere spirituin, fervido alhuc et coinjote mentis pectore, intelligit recoratus carmeu a se compositum, quo vulıeratum militem per ejusmodi mortis imn:rincm obiisse tradiderat, versus ipsos retulit; eaque illi suprema vox fuit." (Ibid., liber $x \nabla, 2$ ro.)

IV, Esop bas well indicated the necessity of fair play amougst the parts of the living body in that noted fable, "the belly and the members", which the the living body in that noted fable, "the belly and the members", which the the early and factious stage of the Roman republic, and which the modern physiologist might often remember with advantage.

physiologist might often remember with advantage. Wilsou Philip. But the blool lost during the careful removul of the brgin Wilsou Philip. But the blood lost during the careful removal of the brain
alone has always rendered me dissatistied with the results obtained. At alone has always rendered me dissatistied with the results
some future day I may refer specially to these experimes is.

some future day I may refer specially to these experimeds.
$:$ Ou this print, see the excellent and common sense remarks of Dr. Bos. \%u this point, see the excellent and common gense remarks of Ir. Bos-
tock, in referance to Sir Benjumin Brodie's experinieutal researches on the canse of the animal temperalure. (Physiology, p. 448. Third edition, 1836.) ments after removal of the cerebro-spinal axis, it would bo necessary first to find out how long the heart will continue forcibly to beat with the nerrous system perfect, but with the digestive process entirely arrested-how long, in short, the same circle of blood will make its rounds freely, supporting the tissues, and undergoing at every moment a chemical change, without the reception of ner pabulum from the abdominal viscera.

But adverting to another subject, the action of narcotic substances taken into the body, whether by inhalation, digestion, or direct introduction into the circulation, affords a good example of the fact that what are considered purely as nervous functions, viz., consciousness, sensation, and all voluntary motions, may be fairly and fully suspended, withthe heart ceasing to beat, or, indeed, without its undergoing any very extraordinary change.

An animal under the profound influence of chloroform, can scarcely be said to gire evidence of a single function of a nerrous kind; it feels not, it sees not, it hears not, it tastes not, it moves not, it thinks not-it is as an animal without a nervous system at that moment, as a plant of a low order, or as an acephalous child in the womb of its mother. Yet the heart of the same senseless being beats on in opposition to the general death; and, if the administration of the poison is stopped, it succeeds in time, not only in recovering its own full force, but in releasing the nervous system itself from its bondage, by driving the destructive agent out of the body through the various eliminatory channels. The effects here indicated are even more forcibly brought out in narcotism with the fumes of the lycoperdon giganteum, than in narcotism from chloroform : while a hybernating animal affords an instance of complete suspension of the nervous functions, with continued action of the heart for weeks and months at a time.

Lastly, in speaking of the effects of narcotic poisons on the heart, what can more remarkably show the independence of that organ of any nerrous influence, than the well known fact that an animal may be so completely narcotised with the Woorali poison, that the natural function of respiration may absolutely cease, while yet the heart rewains in such active motion, that if a little continued assistance be rendered it in the way of artificial respiration, it shall succeed in driving out of the body the poisonous principle in the course of a few hours?*

To pursue another line of argument. Let me recall attention to the fact, that the most important derangements and diseases of the cerebro-spinal axis may be present, without the action of the heart being seriously disturbed. The nerrous centres may be softened in structure, may be pressed on by tumours, bone, or coagula, and every form of paralysis may present itself in other parts of the system; almost the whole of the body, indeed, may suffer some impairment of function; and still the heart, so long as it is supplied with blood, shall play on, and, by distributing faithfully that which it receives, shall contiuue to the last in endearouring to support life.

The records of military and civil surgery afford instances innumerable of injuries of the head of the most serious character, without any remarkable change in the heart stroke of the individuals in whom they occurred. The standard case of Mr. Cline's, related by Sir Astley Cooper, in which a sailor, after receiving a fracture of the skull, laid for thirteen mouths dead to all intents and purposes, except that his stomach assimilated, his chest played, and his heart pumped, indicates clearly how independent the heart is of everything, save the acts of respiration and digestion.

If I were inclined to admit, for discussion's sake, the proposition that diseases of the convulsire type have for their prime and only source a disordered nervous action, I might refer to the steadiness of the heart's beat in the midst of the most violent commotion of the voluntary muscles, as in

- Mr. Waterton and Professor Sewell kept an ass poisoned with wourali alive for four bours by meuns of artiticial resplutation. The animal recovered and lived tor yeurs under the name of Wuoralia. (See Waterton's Vander. ings. Third edition, p.84.) 
chorea, epilepey, tetanus, and hysteria; but I do not allow the truth of the proposition, and I cannot therefore in honeaty force the inference that might be drawn from it.

The relation of the heart to the nervous system in the early periods of embryonic life, is another subject which deserres particular regard. Without desiring to press the statement that there exists in vertebrate animals a pulsating organ, which afterwards becomes the heart, previous to the development of the elements of the uervous system, this must be contended for, that there is such a pulsating organ long previous to a connexion by nerrous cords between it and any nerrous centre. The first strokes of the embryonic heart are consequently independent of nervous influence; and, as these first pulsations cannot but be taken as the types of all that are to follow, on what grounds can we reasonably suppose that the heart will in after life become dependent on a system, which it must itself be continually supplying with power to ensure the necessary reaction on itself?

It is scarcely necessary to state the general fact, though it comes in well at this place, that throughout the animal creation, the size and power of the heart, and the activity of the circulation, bear no relation to the development of the nervous system in general, or of its particular ganglia.

On the grounds, then, that blood can only reach the brain in proportion as it is propelled thither by the heart; that, in syncope, the return of the leading functions of the nervous system is secondary always to the return of the heart's beat; that the action of the heart may fail, while the functions of the nervous system generally remain unaffected except secondarily to the failure of the heart itself; that the cercbro-spinal axis being removed, or its functions destroyed, by the influence of narcotic agents, the heart will act so long as artificial respiration is kept up; that the fotus in utero will live without the brain and cord; that the most serious and extensive injuries and diseases may sometimes happen to the nerrous system, without any extraordinary modification in the action of the central circulating organ; that in embryonic life the pulsations of the heart precede any kind of connexion betwecn itself and the nervous centres; and that the size and power of the heart are not in any way related to the general or special developments of the nervous system of any animal-on these grounds, I dispute the general thesis, that the brain exercises any direct influence over the heart; or that the recumbent position of the body relieves in syncope, by supplying the brain with blood in the first place, and the heart with renewed nervous energy in the second.

I am aware that it is no easy matter to obtain a victory over the two points, the correctness of which I here take the liberty of doubting; since they descend from high authorities, and receive a prominent but false support from one or two collateral facts, which I am desirous neither to ignore or avoid. I have been reminded, for instance, of some experiments of Sir Astley Cooper, in which that distinguished surgeon checked the circulation of the blood passing through the arteries ascending to the brain, and produced death by bringing on an arrest in the play of the heart. These experiments, howerer, in the perusal of which I have spent much time, though highly interesting and valuable as experiments, have led to very incorrect deductions, from the simple fact that the results derived from them were attributed to a false cause. Sir Astley found that, when the vertebral and carotid arteries were ticd simultaneously in a dog, the animal recovered from the effects of the operation; but that if a rabbit were the animal operated on, the two vessels had to be tied at different periods, or death resulted. The inference that sprang out of these experiments was, that the death in the case of the rabbit, when the two arteries were simultaneously compressed, arose from a suppression of the blood flowing to the brain. It is obvious, however, that if such a sudden suppression of the blood going to the brain would at once destroy a rabbit, it would as readily destroy a dog, inasmuch as the anastomosis of vessels is as free in the former as in the latter animal-and as anastomosis cannot be set up imme- diately. But if re examine eloeely into the peculiarities of the hearts of these animals, and inquire into the effects on the heart, which arise from a sudden shortening of the vascular circuit, we shall detect a distinct cause for the varying results, without having the slightest occasion to resort to the mere idea of a checked supply of blood to the brain.

It is probable that almost every physiologist will assent to the simple mechanical proposition, that if two of the main vessels leading from a heart are compressed by a ligature, and the currents of blood flowing through them are fairly cut off, the heart itself must for a brief period succeeding be deranged and overburthened by the increased load of blood that is thrown upon it. It is obvious, indeed, that the dilatation of smaller vessels into larger ones, by which the principle of anastomosis is carried out, depends for its origin and completion on an increased power in tho beat of the central circulating organ. That this proposition. is really true, I shall prove at some future time by reference to experiment. Whenever, therefore, an important obstacle, such as I have described, is thrown in the way of the circulating current, the diffculty will be disposed of, if disposed of at all, by the heart having sufficient muscular power to resist it, and to open free channels for the re-conveyance of blood through the parts in which the suppression occurs. It thus follows that, if a similar operation for the ligature of arteries be performed on any two animals, the results will vary with the muscular power of the heart in each. And on this fact alone, as I believe, depended the difference in the operations on dogs and rabbits performed by $\operatorname{Sir} A$. Cooper. The dogs bore the simultaneous occlusion of two large arterial channels, because their hearts were powerful enough to drive on the blood-current in spite of the obstacle. The rabbits died, not because blood was turned off from their brains, but because their hearts, naturally feeble in structure, succumbed under the burthen to which they were exposed. Thus Sir $\Lambda$. Cooper's experiments teach us the on simple, though all-important fact, that the success that shall follow the tying of a large artery has for one of its elements the capabilities of the heart, from which the vessel springs, to meet an emergency.

A second argument in favour of the direct influence of the brain on the heart is, that failure of the heart, ending in syncope, is not uncommonly the effect of a sudden mental emotion. This, it is affirmed, cannot but be evidence of a primary action on the brain, and secondary from the brain on to the heart. Dr. Alison is constantly harping on this string; and, at the meeting of the Medical Society of London, when the abstract of this paper was read, one of the Fellows, my friend Mr. Hinton, brought forward the same argument, as proof indisputable of the incorrectness of my views. But when the assumption of the direct influence of the brain on the heart is taken up calmly, even on this high ground, it falls in twain. The influence on the heart in cases of fright, is not a direct act. from the brain to the heart, but from the brain to the organs of respiration and common rolition, and through them to the circulating organ. It is the voluntary and semi-roluntary muscles that fail first. The frightened man. forgets to breathe, and fails to move, just for the opposite reason that the collected man, when about to make a violent effort, invariably preludes the attempt with a long and well sustained inspiration. Failing to inspire, then, the heart of the frightened man necessarily flags, and that so quickly, that its inaction does look at first sight very much like a direct failure, derived from the brain.

That the effect of a mental emotion on the heart is of the indirect kind, is shown by the fact that, in some cases where such emotions have caused death in persons suffering previously with a wcakened condition of the cardiac structure, the walls of the heart on the right side have been found ruptured, and the lungs congested. The rupture of the heart in these cases arises clearly from a mechanical cause. The circulation through the lungs has become impeded, and, in endearouring to force on the blood in the face of the difficulty, the enfeebled heart has burst. A healthy. 
heart, under like circumstences, would only be temporarily put about, and might recover itself in time.

The means, too, which we adopt to restore persons suffering from fright or mental emotion, are directed specially to the respiratory organs. We put ammonis to the nose; we supply plenty of fresh air; we dash water on the chest. These measures, so successful in the majority of cases, have no direct effect on the heart; but they stimulate the respiratory muscles into new play; they make the patient aigh and inspire deeply; they re-establish, in short, the normal respiration; and the heart, thus freed of its chains, soon responds to the improvement, and beats in true time.

But the best mode that the inquirer can pursue to assure himself of the order of symptoms in cases of syncope from mental emotion, is for him to watch those symptoms in a case of the kind, as every practitioner of medicine can soon and readily do. Timid women, about to have teeth extracted, are good subjects for such observations. The first step of the process of fainting in such cases begins some time before the peculiarly marked symptoms of syncope appear, perhaps, indeed, before the patient is positively feeling faint ; and that first step, which may be going on for a great many seconds, consists in a well marked modification of the respiratory movements. The breathing is irregular, subdued, and slow. The pulmonic circulation being thus disturbed, the heart soon becomes embarrassed, and palpitates so palpably that the person fainting feels it. This palpitation is but a struggle on the part of the heart to free itself; and occasionally it so far succeeds that recovery takes place without the manifestation of further failure; in other cases, the primary cause continues, and the heart, unable to speed on, fails also more or less; the whoie circulation is thus arrested, and the organs of sensation and motion losing their support (the blood) fall into a state of temporary death. The train of symptoms I have here marked out are not only analogous to, but are identical with, that variety of syncope which frequently comes on in weakly persons after a form of violent exercise, such as running or rowing. Here the respiratory muscles, tiring under the exertion, at last almost cease to act, rendering their possessor, as the people happily express it, "breathless", with his heart palpitating violently, his face pale as marble, and with his own internal sensatious intimating that, if he does not put a stop to his violence, it will soon put a stop to him.*

The influence of the respiration on the motion of the heart is a physiological subject of very ancient date. It particularly interested Haller, who made several shrewd and correct observations concerning it. That immortal philosopher erred, however, in that he looked at the matter in too mechanical a manner, and that he did not understand those beautiful chemical views which have been developed in more modern times; though he was well acquainted, I presume, with the general fact that the heart's action speedily fails during a prolonged expiration, and is as quickly restored by a renewed inspiration.

Iwo years since, while watching a patient in conjunction with my friend Dr. Willis, I had an excellent opportunity for observing the depressing effect on the heart of a prolonged expiration. The patient had for some months previously been paralysed in his upper and lower limbs; but the respirations, the heart-beats, and the digestive functions, continued good, so that he lived on without any

- There is another sensation often arising immediately from fright, which people not uncommonly describe as "the heart rising into the nouth"; by which is implied a kind of leaping sickeniug sensation in the chest, of a very marked and disagreeable character. As the heart has no point of at tachmen towarls which it could be drawn, it is absurd to suppose that the selisation comes from the heart, according to the popular opinion. It is obviously connected with irregular movements of the diaphragm; and indicates that the respiratory muscles are the first to suflier in syncope from mental shorks. In a case of sudden death, after a brief inhalation of chloroform, which occurred lately at St. George's Hospital, the fatul result $w$ as uwing, I doub not, to syncope or syncopal esphyxia, induced, not by an over-dose of tho enæsthetic, but by the patient in her agitation failing to breuth with force sufficient for the maintenance of life. On this case, sce a letter in the Medical Times and liazctle of June 10th, by Dr. Snow, whose writings are a ways characterised by remarkable clearness of thought and strict adherence to broad physiological principles. immediate sign of death. At last, the respirations became irregular, and danger showed itself. The irregularity of the movements of the chest was of the following kinda long and deep inspiration; an immediate, free, and quick expiration; a pause, varying from three to five, and often to ten, seconds. It seemed indeed sometimes-the interval of no breathing was so marked-as if another breath would never be taken. This state lasted for more than twelve hours, and the modification in the radial pulse and in the beat of the heart was the following. During the interval between the termination of the expiration and the recommencement of the inspiration, the pulse was at a positive stand, and the heart-beat was not audible. As the chest filled with the inspiration, the pulse rapidly rose, making eight or ten powerful beats, and continuing to beat until the end of the expiratory act. As time went on, this state of the respiration and circulation became still more remarkable; the result being that the heart so completely stopped during a long pause in the respiration as not to start again with the filling of the chest, upon which the breathing, too, soon ceased of necessity, leading to that absolute change in the character of the body which we describe in the monosyllable death.

The effect of the breathing on the heart may indeed be easily detected by the examination of the heart of a healthy person during forced inspirations and expirations. From several experiments of this kind, I find, first, that the heart always beats a little more rapidly during an inspiration succeeding to a prolouged expiration; second, that, at the termination of either a prolonged inspiration or expiration, the heart-beat begins signally to fail, this failure being by far the most marked at the end of the expiration. Indeed, the heart may be brought to what seems a complete stand for three or four seconds in persons who have the power of refusing to inspire for a little time, after a long and slow process of expiration; and I doubt not that the peculiar faculty of stopping his heart, possessed by Colonel Townsend, of famous physiological memory, is explainable on the principles and facts I have here laid down.

As I before said, IIaller and his cotemporaries were well aware of the intluence of the respiratory movements on the beat of the heart, and had the facts of that influence correctly before them. In trying, however, to explain these facts on simple mechanical grounds, they necessarily failed because it was shown that the lungs might be compressed from fluids injected or exuded into the pleural cavities, without exciting any modification in the frequency or force of the heart-beat, although the breathing was quickened and rendered laborious by the compression. We know in this day that the influence of imperfect respiration on the heart is in part chemical and in part mechanical. We have learned that the lungs may be fully inflated with gaseous substance, and yet that the heart will stop quickly, unless the same gas contain oxygen in due quantity, of pure quality, and unmixed with any agent that shall check its free combination with oxidizable materials. We also are aware that if a free chcmical communion between blood and oxygen does not constantly take place in the lungs, the blood can no longer make the pulmonic circuit freely, and that the right side of the heart speedily receives an overplus of blood, and the left side a diminished portion in consequence.

In the remarks I have made on the influence of respiration on the heart, I have referred to experiments in which the inspirations and expirations were intentionally and forcibly modified. These kind of inquiries, howerer, only affect the question of syncope from mental emotion indirectly. In cases of this kind, there are no forcible and prolonged inspirations or expirations, but a diminution below the natural standard in the extent of each-a much more serious matter; for when a person takes in deep inspirations, and throws off free expirations, or when, on the contrary, he takes short and quick inspirations and expirations, he may breathe sufficiently, though irregularly; and the result will be, that the heart will follow in the same train, and will beat with sufficient force, but not in true time 
-a condition not absolutely inimical to life. But, in fainting, the bresthing is actually slackened; the inspiritions are $f e w$ and faint; the expirtions are in proportion; the free chemical action, therefore, that should take place in the lungs does not occur, and the heart, unable to drive the blood round from its right to its left side, fails inevitably. It is probably in a similar way that over doses of chloroform, ether, hydrocyanic acid, and many. other substances, destroy life, when receired into the lungs in rapour. Electricity, too, kills perhaps in like manner, ns well as several other instruments of death which produce what is called asphyzia; for, when an animal dies in a few seconds from any sudden derangement in the heart or lungs, the distinctions between syncope and asphyxis taper down to very fine points indeed.

The effects of blows on the epigastrium, producing sudden death from syncope, have been pointed out to me as proofs that the heart is subject to a direct influence derived from the cerebro-spinal axis: for what, it is asked, can cause death in these cases, except that the blow given comes direct upon the solar plexus of nerves, the shock to which is immediately communicated to the cerebro-spinal axis, and thence to the heart? It is almost impossible to refute, in language strong enough, this shallow explanation of the effects of blows on the stomach; which, in truth, most physiologists admit to be an hypothesis rather made to fill up a gap temporarily, than as one bearing an air of probability. The intluence of a blow in the epigastrium, in producing syncope, is to my mind explainable on the simplest principles. As a sharp stroke across the elevator muscles of the arm paralyses them, and takes from the motion of the limb, so a blow on the epigastrium, coming directly, as it must, into contact with the diaphragm, paralyses that muscle, and puts an immediate stop to inspiration. Why the heart should fail under such circumstances, is sufficiently plain after what has been already written. The common expression used in reference to such cases, "that the wind has been knocked out of the body", may thus be considered as conveying not only a correct idea of what seems to occur, but a correct description of what actually does occur.

In the foregoing remarks, then, I have tried to prove that there is no direct connexion between the functions of the brain and the action of the heart. To some minds, so much evidence in the way of disproof will be considered unnecessary - such minds, I mean, as would consider the question on broad principles of the $a$ priori character, and would argue that no one who understands the wisdom of nature would imagine that the heart should be placed in any direct connexion with the mind, or the mind's organ, to be swayed about by every passing thought, to be squeezed on itself like the hand, or shut up and opened at discretion, like the mouth. The same reasoners might also urge that the heart, as Harvey long ago pointed out, and as has been proved over and over again since, is without sensation; that we feel not the motion of its blood passing through it, or of its valves opening and shutting; and that, in fact, if we did not hear it now and then, when it is much put about, or feel it tilting against sensitive structures, we might live to the age of Methuselah, and not know from any evidence unconnected with anatomical learning that the space filled up by an organ so constantly moving was filled up by anything at all. I would, however, remind reasoners of this class, first, that numerous physiological problems are thickly overlaid with fantastically devised mysteries, which some defend and admire because they render such problems too profoundly complicated either to be understood by the ordinary and common-sense processes of human thought, or to be recognised by the queen of nature herself as containing even the germs of original conceptions emanating from her; secondly, that however certain a physiologist may feel that he sees a simpler explanation of any fact than that which is commonly given, he ought, out of respect both to courtesy and valour, to be prepared to discuss the whole question, and to shrink from no point that may be thrown in opposition, be it erer so strong or erer so absurd. It is from these motive that the preceding paren bove. simpler explenstion of the good effects of the harisental: posture in syncope, then that which has been offered bj many eminent writers, and which is still seslously tanght in our schools; and, anxious "to put off the old becore, putting on the new", I have entered carefully into a refutetion of all those arguments in farour of a direct relationship between the nerrous system and the heart, on which the old theory is based. I can now without hesitation doseribe my own views.

\section{Mortlake, June 1854. [To be continued.] \\ FURTHER OBSERVATIONS \\ ON THE ATMOSPHERIC CHANGES RELATING TO CHOLERA.*}

9

By J. A. Hingeston, Esq.

Th८т an overcast sky and damp weather alone are not the only conditions requisite for the development of the Asiatic cholera, the metoorology of the month of June, just ended, is sufficient to testify; for, with the exception of about ten days, the whole of that month has been cloudy, misty, or rainy, and yet cholers has not prevailed At the same time, it must be admitted that sereral indications of the disease being close at hand have not been wanting. Thus, two deaths from cholera were registered, the one at Mile End New Town on the 26th, and the other in Limehouse on the 27th of May; showing that a state of atmosphere of a choleraic character had preceded their appearance by two or three days. On referring to my diary of the weather, I find the following entries. (Table I.)

About tho 31st of May, diarrhcea presented itself in this town, as was pointed out to me by Dr. Bayes, one of the Physicians of the Brighton Dispensary. In the preceding table of the weather, it must be remarked that, although there was both rain and a calm, yet the other conditions that usually accompany the outbreak of cholera were altogether absent. For instance, the mortality was above, and not below, the average; the barometer stood at change, instead of at fair; and it was rainy and wet, instead of being moist and $d r y$, as is the case during the cholers periods. All these indications tend to prove that the perticular element, be it what it may, which constitutes the active principle of the disease, and presses up the mercury in the barometer to fair in the midst of a cloudy moist atmosphere, was not present on the occasion just quoted, or at least was not present in any degree of intensity.

In addition to the foregoing remarks, I wish to draw the attention of those who study this interesting question to the fact that, besides these remote signals of the proximity of cholera in the atmosphere, there were other symptoms of its being likely to occur observable in the pathology of the prevailing character of disease. Jaundice has been frequent during this spring, and an indigestion in the form of subacute gastritis. The urea, which was obvious in the urine previous to the month of March, has greatly diminished, or it has entirely disappeared. The specific gravity has been low, and once I observed the phosphatic character, which seemed to arise from some unassignable cause, as no disease was present that could reasonably account for it.

But, during the month of June, there were three days marked by all the essentials of the choleraic atmosphere, which, had it continued, would quickly have produced the disease in its worst form. The following is the extract from my diary. (Table II.)

No cases of cholera were registered in Iondon subsequently to these three remarkable days; but eighteen cases were reported at Glasgow about this time, and a number of deaths. The local authorities imputed the outbreak of the disease to the "removal of a number of wells which had

- Vide Asgociation Joprad, 21at April, 186, p. ofs. 